Mens

revue d'histoire intellectuelle de l'Amérique française

\title{
Antoine Compagnon. Les antimodernes, de Joseph de Maistre à Roland Barthes. Paris, Gallimard, 2005. 464 p.
}

\section{Éric Bédard}

Volume 8, numéro 1, automne 2007

URI : https://id.erudit.org/iderudit/1023149ar

DOI : https://doi.org/10.7202/1023149ar

Aller au sommaire du numéro

Éditeur(s)

Centre de recherche en civilisation canadienne-française

ISSN

1492-8647 (imprimé)

1927-9299 (numérique)

Découvrir la revue

Citer ce compte rendu

Bédard, É. (2007). Compte rendu de [Antoine Compagnon. Les antimodernes, de Joseph de Maistre à Roland Barthes. Paris, Gallimard, 2005. 464 p.] Mens, 8(1),

127-131. https://doi.org/10.7202/1023149ar d'utilisation que vous pouvez consulter en ligne.

https://apropos.erudit.org/fr/usagers/politique-dutilisation/ 


\section{Comptes RENDUS}

\section{Antoine Compagnon. Les antimodernes, de Joseph de Maistre à Roland Barthes. Paris, Gallimard, 2005. 464 p.}

Les historiens intéressés par les idées, attentifs aux concepts, à l'affût d'explications nouvelles qui rendraient le passé moins opaque, ont tout à gagner à lire certains collègues littéraires. C'est qu'on ne lit pas seulement François Ricard ou Pierre Nepveu pour en apprendre plus sur la littérature d'ici et d'ailleurs - même si leurs écrits sont très instructifs - mais bien davantage parce que, à chaque fois, on a le sentiment de croiser des esprits libres, de véritables humanistes qui transcendent, par l'essai, ce qu'on appelle pompeusement les «sciences de l'homme». On les lit aussi pour l'élégance du style, la souplesse de la démonstration en même temps que pour leurs intuitions fortes sur notre temps. J'espérais retrouver ce plaisir de lecture en me plongeant dans le livre du réputé Antoine Compagnon, auteur de Les antimodernes, de Joseph de Maistre à Roland Barthes. Je souhaitais que cet ouvrage, découvert un peu par hasard, me fasse envisager autrement une tradition de pensée plus que discréditée par la modernité rugissante. Je n’ai pas été déçu.

Dans ce livre à la fois dense et généreux, cet historien de la littérature française, spécialiste reconnu de la troisième république des lettres, nous présente une tradition de pensée que l'on assimile généralement à la pure Réaction mais qui, de son point de vue, n'est autre chose que la modernité en action. D'entrée de jeu, Compagnon distingue les antimodernes des traditionalistes, des réactionnaires, voire même des conservateurs qui ont proposé et qui proposent toujours, dans l'ordre politique, de stopper la marche du temps 
ou qui prônent le retour aux valeurs anciennes, sinon à l'Ancien régime. Les antimodernes que nous présente ce professeur de l'Université Columbia sont bel et bien des modernes, mais des «modernes en délicatesse avec les Temps modernes » (p.7), des «Reluctant Moderns » (p. 216), c'est-à-dire des modernes qui doutent, des modernes déchirés, des modernes ambivalents qui refusent de souscrire aveuglément aux dogmes qu'on associe généralement à la modernité : progrès, rationalisme, déterminisme mécaniste, matérialisme. En même temps, ces antimodernes savent qu'on ne pourra jamais revenir en arrière, qu’on ne pourra jamais. "défaire, selon la formule célèbre de Paul Bourget, l'œuvre meurtrière de la Révolution française ». Ces antimodernes sont conscients que la modernité a triomphé, ils ne considèrent pas cette victoire comme un simple accident de l'histoire. Ils craignent cependant que ce triomphe ait un goût amer. Cette crainte sourde, ce «fatalisme libéré du ressentiment » (p. 444), les amène à se battre, avec l'énergie du désespoir, pour ne pas que cette modernité ne fasse taire, pour toujours, les voix du passé, pour ne pas qu'elle balaie du revers de la main les héritages accumulés au fil des siècles. En d'autres termes, si l'antimoderne est pris par le mouvement de l'histoire, il semble « incapable de faire son deuil du passé » (p. 13). Une optique que résume magnifiquement Roland Barthes qui se présenta, à la fin de sa vie, comme le parfait représentant de «l'arrière-garde de l'avant-garde » : " être d'avant-garde, précisa-t-il un jour, c'est savoir ce qui est mort ; être d'arrière-garde, c'est l'aimer encore ». (Cité dans p. 13.)

L'antimoderne est aussi un moderne parce que sa nostalgie de l'Ancien régime, sa mélancolie face à ce qui disparaît de façon irrémédiable, sa vision idyllique des formes organiques de la vie sociale d'autrefois, d'un mot sa posture ombrageuse devant l'optimisme progressiste, s'exprime à la 
manière des modernes. L'antimoderne ne parle pas au nom d'une caste aristocratique ou d'un parti, c'est au contraire un individualiste qui use du droit de parole que lui confère la modernité pour exprimer contre elle toute sa hargne. Exilés malheureux, puis, souvent, "émigrés de l'intérieur ", les antimodernes se nourrissent de leur expérience personnelle $\mathrm{du}$ temps, de leur vie intérieure de sujets modernes, pour écrire des œuvres fortes et sans concessions. Paradoxalement, les antimodernes, ce sont donc ceux qui, avec force et véhémence, profitent les premiers de cette liberté de parole chèrement acquise avec la modernité ; ce sont ceux qui ne craignent pas d'être anticonformistes, qui agissent, souvent, en solitaires face à la foule optimiste qui rejette ou comprend mal leur posture critique. C'est par ce paradoxe apparent que Compagnon en vient à qualifier l'antimodernisme de " modernisme véritable» (p. 12) et les antimodernes, de «modernes en liberté » (p. 14).

Pour nous convaincre de cette thèse pour le moins audacieuse, Compagnon divise son ouvrage en deux parties bien distinctes et d'inégales longueurs. La première partie, la plus courte, probablement la plus intéressante pour ceux qui ne sont pas des spécialistes de l'histoire littéraire française, traite des «idées». En six chapitres, Compagnon tente de caractériser cette posture des antimodernes. À la fois historique - ils prônent la contre-révolution -, philosophique - ils sont d'ardents critiques des Lumières -, morale - ils affichent un pessimisme face à ce que l'avenir réserve -, religieuse - ils croient au péché originel -, esthétique - ils sont fascinés par le sublime - et stylistique - ils pratiquent mieux que quiconque la vitupération -, la posture des antimodernes, tente de montrer Compagnon, aurait ses propres canons. La seconde partie de l'ouvrage est, quant à elle, consacrée aux "hommes » qui, depuis la Révolution française, auraient le mieux incarné la 
tradition antimoderne. On ne s'étonnera guère de retrouver des auteurs comme de Maistre, Chateaubriand ou Péguy. D'autres noms, cependant, surprennent ou seront moins spontanément associés au camp des « antimodernes "; qu'on pense au critique et historien Albert Thibaudet et, surtout, à Roland Barthes, généralement associé à l'avant-garde telquelienne. Cette seconde partie du livre de Compagnon a moins d'unité que la première. Ses sept chapitres sont d'inégales longueurs et la volonté de démontrer l'antimodernisme des auteurs n'est pas toujours évidente. Plusieurs des portraits offerts sont fascinants - ceux de Péguy, de Thibaudet et de Barthes m'ont semblé les plus riches - mais, d'un chapitre à l'autre, certaines digressions érudites, pas toujours pertinentes à première vue, nous éloignent du thème du livre.

Pour apprécier l'ouvrage d'Antoine Compagnon et comprendre pourquoi il tient tant à distinguer l'antimodernisme du traditionalisme ou du conservatisme, il faut garder à l'esprit qu'il s'intéresse d'abord et avant tout à une tradition littéraire, non pas politique. Une autre sous-thèse du livre est que cette tradition antimoderniste semble mieux résister au temps que la littérature engagée qu'incarnent des auteurs comme Lamartine, Zola ou Aragon. Comme le soutient Compagnon, qui reprend ici une hypothèse de Thibaudet, tout se passe comme si les véritables opposants à l'air du temps et aux valeurs dominantes de l'époque s'étaient réfugiés, comme au XVIII siècle, dans le monde des lettres. Ce refuge dans le monde des lettres découle également d'un rapport particulier au politique. Selon Compagnon, les véritables antimodernes sont ceux qui vont toujours refuser d'être embrigadés par une cause ou un parti. Face à la politique, les antimodernes font souvent figure de dandys hautains ou de " francs-tireurs ", leur « apolitisme » aurait même quelque chose "d'esthétique » (p. 446). Ce refus du politique, qui est aussi une peur typique- 
ment moderne de l'enrégimentement, est tout à fait dans l'ordre des choses, selon Compagnon, car les antimodernistes sont de véritables écrivains pour qui l'impossibilité à réformer concrètement le monde moderne est « la condition de possibilité de la poursuite indéfinie de l'entreprise littéraire » (p. 445). Cela explique pourquoi Compagnon n'inclut pas dans sa tradition antimoderniste des écrivains comme Maurras ou Drieu La Rochelle qui, dans les deux cas, vont prendre clairement parti qui pour la restauration monarchique, qui pour le fascisme.

Ce confinement de l'antimodernisme au champ littéraire constitue l'une des limites de l'étude d'Antoine Compagnon. On aurait souhaité qu'il creuse davantage, dans la première partie de l'ouvrage, cette distinction tranchée entre l'antimodernisme et le conservatisme. De même, le concept de "modernité » aurait mérité une vraie définition. Compagnon semble tenir pour acquis que celle-ci débute avec la Révolution française. Or, à tout le moins sur le plan de la chronologie historique, on a longtemps fait débuter la « modernité » avec la renaissance. Cela dit, pour qui cherche à ressaisir la pensée occidentale des deux derniers siècles autrement qu'à travers les éternels couples Progrès/Réaction, Gauche/Droite, Modernité/Ancien régime, le livre d'Antoine Compagnon est à la fois pertinent et stimulant. Il fera découvrir, ou redécouvrir, des essais pénétrants d'auteurs français qui, sans le jargon et l'enflure des postmodernistes, proposent des critiques pertinentes de la modernité.

Éric Bédard

Télé-Université

Université du Québec à Montréal 